\title{
Ultrasound findings and clinical antecedents of cerebral palsy in very preterm infants
}

\author{
Deirdre J Murphy, Peter L Hope, Ann Johnson
}

\begin{abstract}
Objective-To investigate the incidence and timing of neonatal ultrasound lesions, and clinical details about pregnancy and the perinatal period, in a total population of extremely premature children with cerebral palsy, born to mothers who were resident in Oxfordshire.

Methods-Eighteen children born at less than 32 completed weeks of gestation were identified from a regional cerebral palsy register. Eighteen controls were matched for gestation, time, and place of birth. Perinatal records and ultrasound reports were systematically reviewed. Sequential neonatal ultrasound images stored on videotape were reanalysed, blind to the outcome of the infants.

Results-Sixteen (89\%) of the cerebral palsy cases and one (6\%) control had parenchymal cysts on neonatal brain scans. Of the cerebral palsy cases, none had cysts detectable on the first day. Six developed cysts within the first 10 days of life, and two of these had periventricular echodensities when first scanned postnatally. Antenatal complications were recorded in 16 cases and nine controls. The early postnatal appearance of cysts in a few babies with a history of severe antenatal complications suggested that antenatal factors may have contributed to the cerebral pathology.

Conclusions-Intrauterine factors may have contributed to adverse neurological outcome, but $16 / 18$ of the preterm cerebral palsy cases had an associated cerebral lesion which developed in the perinatal period.
\end{abstract}

(Arch Dis Child 1996; 74: F105-F109)

Keywords: preterm, cerebral palsy, ultrasound, clinical antecedents, antenatal, parenchymal cyst.

National Perinatal Epidemiology Unit, Radcliffe Infirmary, Oxford

D J Murphy

A Johnson

Special Care Baby Unit, John Radcliffe NHS Trust, Oxford P L Hope

Correspondence to: Dr D J Murphy, c/o High Risk Office, Level 6 Women's Centre, John Radcliffe NHS Trust, Headley Way, Oxford OX3 9DU.

Accepted 22 November 1995

C Crown copyright 1996

Cerebral palsy occurs in between $8-10 \%$ of very preterm babies. ${ }^{1}$ The cerebral damage is thought to arise around the time of birth when the brain is particularly vulnerable to haemorrhage and ischaemia. ${ }^{2}$ Brain imaging, in particular ultrasonography, has been used to explore the nature of cerebral abnormalities in the preterm brain and their association with neurological impairment. In this study we examined the cerebral ultrasound features in the neonatal period of a total population of very preterm babies who developed cerebral palsy and compared them with a group of very preterm controls.

Cerebral palsy in very preterm babies is assumed to originate predominantly in the postnatal period although there is evidence that it is antenatal in origin in some babies. ${ }^{3-6}$ Ultrasonographic and postmortem studies of the evolution of cerebral abnormalities suggest that cystic lesions develop over 10 to 14 days, ${ }^{7-10}$ and are preceded by parenchymal echodensities. ${ }^{11}$ The time at which ultrasound echodensities and cysts first appear may be crucial in pinpointing which clinical antecedents are important. To investigate the timing and clinical correlates of clinically important abnormalities requires sequential ultrasound scans for each baby.

We therefore compared sequential scans from a total population of very preterm babies who developed cerebral palsy with a group of very preterm controls to address the following questions. First, what is the incidence of cerebral abnormalities in very preterm babies who develop cerebral palsy and how do they compare with controls? Secondly, when do these lesions develop; and thirdly, what if any are the clinical correlates with these lesions?

\section{Methods}

All subjects were singletons born at less than 33 weeks gestation between 1987 and 1990. The mothers were residents of Oxford district and gave birth at the John Radcliffe Maternity Hospital. Babies who did not survive to discharge were excluded. Multiple births were also excluded from this study as current evidence suggests that the risk factors for cerebral palsy in this group differ from those in singleton births. ${ }^{12}$

Gestational age for all groups was estimated by using a combination of menstrual dates and an ultrasound scan performed before 20 weeks of gestation. The scan date was preferred if the menstrual date was uncertain or if there was a discrepancy of more than 14 days between the menstrual date and the scan estimate.

Eighteen children with cerebral palsy, from a geographically defined population, were identified from the Oxford region register of early childhood impairments. ${ }^{13}$ The definition of cerebral palsy used by the register is that of a permanent impairment of voluntary movement or posture presumed to be due to permanent damage to the immature brain. The register includes children of mothers who were resident within the former Oxford health region at the time of delivery. Multiple sources of ascertainment are used to compile the register, and the condition of the children is determined at the age of 3 and 5 years.

Eighteen controls who did not have cerebral age and as near as possible for date of birth. palsy were selected and matched for gestational 
ULTRASONOGRAPHY

Serial cerebral ultrasound examinations had been recorded and stored on videotape. Ultrasound scanners were the ATL 300C (Advanced Technical Laboratories) until 1988, and the UM4 (ATL) thereafter, with $7 \cdot 5$ $\mathrm{MHz}$ transducer heads. For retrospective review, four recordings were selected and reviewed for each baby. These were taken from the first 24 hours, between 25 and 72 hours, between 5 and 9 days and at about 6 weeks. The findings were described using a classification modified from a datasheet used in a previous trial (OSIRIS). ${ }^{14}$ The right and left cerebral hemispheres were described separately in terms of germinal layer/intraventricular haemorrhage, parenchymal echodensity, ventricular dilatation and parenchymal cysts. Moderate ventricular dilatation was assigned where the ventricular index was above the 97th centile and hydrocephalus when the dilatation was more than $4 \mathrm{~mm}$ above the 97 th centile using a centile chart from Levene et al (1981). ${ }^{10}$ Parenchymal cyst was an umbrella term used for any parenchymal echolucency suggestive of a cavity. These lesions were further described as porencephalic where there was a single large echolucent cavity and cystic periventricular leucomalacia (PVL) where the cavities were small and often multiple. All of the recordings were reviewed by the same observer ( $\mathrm{PH})$ who was blind to the identity and outcome of the babies during the scan review.

CLINICAL AND LABORATORY DATA

The obstetric and neonatal notes were obtained and reviewed by an obstetric researcher blind to the child's outcome (DM). Antenatal complications of interest included pre-eclampsia, placental abruption, prolonged rupture of the membranes, chorioamnionitis, urinary tract infection, and pre-existing maternal disease (definitions in Appendix 1). The presence of labour and the mode of delivery were recorded as were characteristics of the infants at birth, including Apgar scores and umbilical cord blood assays. Postnatal complications of interest included prolonged ventilation, respiratory disease, hypotension, patent ductus arteriosus, sepsis and necrotising enterocolitis (definitions in Appendix 2).

\section{STATISTICAL ANALYSIS}

The results of comparisons between cerebral palsy cases and controls are given as the observed difference between proportions (95\% confidence intervals) estimated by matched analysis using the computer programme CIA. ${ }^{15}$ The McNemar test was used to test for significance.

\section{Results}

Four ultrasound recordings were retrieved for 35 of the subjects. One of the cerebral palsy cases had only two scans during his short postnatal admission, thus the overall ascertainment of recordings was $99 \%$.

Of the 18 cases, 16 (89\%) had cystic lesions diagnosed on ultrasonography during the postnatal period (table 1). In seven cases the lesions were bilateral and of the nine cases with unilateral lesions, four had single large porencephalic cysts. Only one $(6 \%)$ of the controls had a cystic lesion and this baby had developmental delay and learning difficulties at follow up. The presence of a cystic lesion was strongly associated with cerebral palsy $(\mathbf{P}<0.001)$. A parenchymal echodensity was diagnosed in 14 cases and two controls; $P<0.01$. The echodensity preceded the development of a cyst in all the cases and in one of the controls. All of the cerebral palsy cases had some degree of ventricular dilatation. Both moderate ventricular dilatation $(P<0.01)$ and hydrocephalus $(\mathrm{P}<0.01)$ were significantly associated with cerebral palsy. Germinal layer/intraventricular haemorrhage occurred in a similar number of cases and controls (table 1).

Of the cystic lesions in cerebral palsy cases, six $(38 \%)$ were present before the 10 th postnatal day and $10(62 \%)$ developed between 10 days and 6 weeks of age (table 2). No cystic lesions were detected in the first 72 hours. However, three $(21 \%)$ infants had parenchymal echodensities in the first 24 hours with no previous normal scan and two of these had developed cysts before day 10. The ultrasound lesions could have evolved postnatally in these infants, but the findings are also consistent with an antenatal onset in the hours or days prior to delivery.

Antenatal complications, caesarean section delivery, and postnatal sepsis occurred more frequently in cases than controls (table 3 ). Among cases of cerebral palsy, antenatal complications occurred more frequently in infants with early (0-9 days) and intermediate (10-20 days) first diagnosis of cystic lesions, and pneumothorax occurred more frequently in infants with late (more than 20 days) diagnosis of cystic lesions.

The numbers in this study were too small to analyse the association between individual

Table 1 Overall No (\%) incidence of lesions ${ }^{\star}$ in cases of cerebral palsy and controls

\begin{tabular}{|c|c|c|c|c|c|c|}
\hline & Normalt & $\begin{array}{l}\text { Germinal layer/ } \\
\text { intraventricular } \\
\text { haemorrhage }\end{array}$ & $\begin{array}{l}\text { Parenchymal } \\
\text { echodensity }\end{array}$ & Cystic lesion & $\begin{array}{l}\text { Moderate } \\
\text { ventricular } \\
\text { dilatation }\end{array}$ & Hydrocephalus \\
\hline $\begin{array}{l}\text { Cerebral palsy cases }(n=18) \\
\text { Controls }(n=18) \\
\text { Difference between proportions }(95 \% \text { CI }) \\
\text { P value }\end{array}$ & $\begin{array}{l}2(11) \\
7(33) \\
-22(-33,9) \\
\text { NS }\end{array}$ & $\begin{array}{l}12(67) \\
13(72) \\
-5(-31,25) \\
\text { NS }\end{array}$ & $\begin{array}{l}14(78) \\
2(11) \\
67(25,78) \\
<0.01\end{array}$ & $\begin{array}{l}16(89) \\
1(6) \\
83(66,100) \\
<0.001\end{array}$ & $\begin{array}{l}10(56) \\
3(17) \\
39(2,50) \\
<0.01\end{array}$ & $\begin{array}{l}6(33) \\
1(6) \\
28(8,48) \\
<0 \cdot 01\end{array}$ \\
\hline
\end{tabular}

*Occurrence of lesions at any time + No abnormality at any scan. $¥$ Difference between proportion (\%), based on matched analysis using the exact method for $95 \%$ confidence intervals (CI). P values calculated using the McNemar test. 
Table 2 Timing of prognostic lesions in cases of cerebral palsy, based on number (\%) with earliest report of abnormality

\begin{tabular}{lllll}
\hline Timing & $\begin{array}{l}\text { Parenchymal } \\
\text { echodensity }\end{array}$ & $\begin{array}{l}\text { Cystic } \\
\text { lesion }\end{array}$ & $\begin{array}{l}\text { Moderate ventricular } \\
\text { dilatation }\end{array}$ & Hydrocephalus \\
\hline 0-24 Hours & $3(21)$ & 0 & $2(20)$ & 0 \\
25-72 Hours & $5(36)$ & 0 & $1(10)$ & $1(14)$ \\
5-9 Days & $5(36)$ & $6(38)$ & $3(30)$ & $2(29)$ \\
@6 Weeks & $1(7)^{\star}$ & $10(62) \dagger$ & $4(40)$ & $4(57)$ \\
\hline
\end{tabular}

$\star$ Earliest report day 13. †Earliest reports days 10, 11, 11, 13, 15, 19, 25, 31, 49, 51.

antenatal factors and the timing of cystic lesions, but the case histories of the seven infants (6 cases and 1 control) with early onset cystic lesions are described as follows:

Case 1 Female; 26 weeks, 751 g, Apgar scores 5,8 , UA pH $7 \cdot 1$, base deficit $14 \cdot 6 \mathrm{mmol} /$.

Prolonged rupture of membranes with acute severe chorioamnionitis, spontaneous labour, vaginal delivery.

Ventilated, moderate hyaline membrane disease (HMD), pneumothorax day 7 .

First scan at 8 hours of age; bilateral parenchymal echodensities.

Bilateral multiple parenchymal cysts at day 5, right more extensive.

Cerebral palsy; left hemiplegia.

Case 2 Male; 27 weeks, $1056 \mathrm{~g}$, Apgar scores 7,9, UA pH 7.06, base deficit $13 \mathrm{mmol} / 1$.

Concealed abruption, spontaneous labour, vaginal breech delivery.

Ventilated, mild HMD, patent ductus arteriosus (PDA) requiring indomethacin.

First scan at 10 hours of age; right parenchymal echodensity.

Huge right parietal cyst at day 9 with bilateral hydrocephalus.

Left hemiparesis.

Case 3 Male; 30 weeks, $1005 \mathrm{~g}$, Apgar scores 8,10 , UA pH $7 \cdot 27$, base deficit $7 \cdot 6 \mathrm{mmol} / 1$.

Severe proteinuric pre-eclampsia, no labour, caesarean section, acute atherosis and infarctions on placental histology.

Ventilated, moderate HMD, necrotising enterocolitis (NEC), renal failure.

First scan normal; bilateral IVH with right parenchymal extension at day 3 .

Huge right parietal cyst and small left cysts with right hydrocephalus at day 8 .

Spastic quadriplegia.
Case 4 Male; 26 weeks, $795 \mathrm{~g}$, Apgar scores 7,8 , UA pH $7 \cdot 31$, base deficit $1 \cdot 8 \mathrm{mmol} / 1$.

Severe proteinuric pre-eclampsia, no labour, caesarean section, placental infarction on histology.

Ventilated, PDA requiring fluid restriction, episode of sepsis.

First scan normal; bilateral IVH with right parenchymal extension at day 3 .

Multiple small right parenchymal cysts at day 9, also left frontal cyst at day 30.

Spastic diplegia and developmental delay.

Case 5 Male; 30 weeks, $1518 \mathrm{~g}$, Apgar scores 8,9 , UA pH $7 \cdot 34$, base deficit $4 \cdot 8 \mathrm{mmol} / 1$.

Major antepartum haemorrhage, three previous preterm deliveries with two neonatal deaths, spontaneous labour, tocolysis, corticosteroids, emergency caesarean section.

Ventilated, moderate HMD, PDA requiring fluid restriction, NEC.

First scan normal, bilateral IVH with right parenchymal extension at day 2 .

Right porencephalic cyst at day 9 with bilateral hydrocephalus.

Left hemiparesis.

Case 6 Male; 28 weeks, 1317 g, Apgar scores 1,4 , no cord blood available.

Previous maternal thyroid resection/ antenatal thyroxine, acute pyelonephritis, spontaneous labour, caesarean section in labour for malpresentation.

Ventilated, moderate HMD, pneumothorax, hypotension, NEC.

? Bilateral parenchymal echodensity day 1 , definite bilateral echodensity day 2

Appearances of PVL day 3, right frontoparietal cyst and small left cyst day 9.

Spastic quadraparesis and developmental delay.

Control Male; 26 weeks, 884 g, Apgar scores 3,6 , no cord gas available.

Maternal pyrexial illness, confirmed as listeriosis on microbiology and placental histology, spontaneous labour, vaginal delivery.

Ventilated, moderate HMD, congenital listeriosis.

First scan bilateral IVH, left temporal echodensity at day 8 .

Single left temporal cyst at day 8 .

Table 3 No (\%) of clinical events for cases of cerebral palsy and controls

\begin{tabular}{|c|c|c|c|c|c|}
\hline & \multicolumn{4}{|l|}{ Cerebral palsy } & \multirow{2}{*}{$\begin{array}{l}\text { Controls } \\
\text { Total } \\
(n=18)\end{array}$} \\
\hline & $\begin{array}{l}\text { Cysts day 0-9 } \\
(n=6)\end{array}$ & $\begin{array}{l}\text { Cysts days } 10-12 \\
(n=6)\end{array}$ & $\begin{array}{l}\text { Cysts > day } 20 \\
(n=4)\end{array}$ & $\begin{array}{l}\text { Total } \\
(n=18)\end{array}$ & \\
\hline $\begin{array}{l}\text { Antenatal: } \\
\text { Any antenatal complication } \\
\text { Placental abruption } \\
\text { Prolonged rupture of membranes } \\
\text { Chorioamnionitis } \\
\text { Maternal infection } \\
\text { Maternal disease } \\
\text { Pre-eclampsia }\end{array}$ & $\begin{array}{l}6(100) \\
1(17) \\
1(17) \\
1(17) \\
1(17) \\
3(50) \\
2(33)\end{array}$ & $\begin{array}{l}6(100) \\
1(17) \\
1(17) \\
1(17) \\
0(0) \\
0(0) \\
3(50)\end{array}$ & $\begin{array}{l}2(50) \\
0(0) \\
1(25) \\
1(25) \\
0(0) \\
0(0) \\
0(0)\end{array}$ & $\begin{array}{r}16(89) \\
2(11) \\
5(28) \\
4(22) \\
1(6) \\
3(17) \\
5(28)\end{array}$ & $\begin{array}{l}9(50) \\
2(11) \\
2(11) \\
3(17) \\
1(6) \\
0(0) \\
1(6)\end{array}$ \\
\hline $\begin{array}{l}\text { Delivery: } \\
\text { Vaginal delivery } \\
\text { Caesarean section, in labour } \\
\text { Caesarean section, no labour }\end{array}$ & $\begin{array}{l}2(33) \\
2(33) \\
2(33)\end{array}$ & $\begin{array}{l}0(0) \\
2(33) \\
4(67)\end{array}$ & $\begin{array}{l}3(75) \\
1(25) \\
0(0)\end{array}$ & $\begin{array}{l}6(33) \\
6(33) \\
6(33)\end{array}$ & $\begin{array}{r}14(78) \\
2(11) \\
2(11)\end{array}$ \\
\hline $\begin{array}{l}\text { Postnatal: } \\
\text { Ventilation }>7 \text { days } \\
\text { Hyaline membrane disease } \\
\text { Pneumothorax } \\
\text { Hypotension } \\
\text { Patent ductus arteriosus } \\
\text { Sepsis } \\
\text { Necrotising enterocolitis }\end{array}$ & $\begin{array}{l}5(83) \\
6(100) \\
2(33) \\
2(33) \\
4(67) \\
1(17) \\
3(50)\end{array}$ & $\begin{array}{l}6(100) \\
5(83) \\
1(17) \\
2(33) \\
3(50) \\
5(83) \\
1(17)\end{array}$ & $\begin{array}{l}4(100) \\
4(100) \\
3(75) \\
1(25) \\
1(25) \\
3(75) \\
0(0)\end{array}$ & $\begin{array}{r}16(89) \\
16(89) \\
6(33) \\
5(28) \\
8(44) \\
10(56) \\
4(22)\end{array}$ & $\begin{array}{c}11(61) \\
13(72) \\
4(22) \\
4(22) \\
5(28) \\
1(6) \\
0(0)\end{array}$ \\
\hline
\end{tabular}


Table 4 Characteristics at birth for cases of cerebral palsy and controls

\begin{tabular}{lcc}
\hline & Cases & \multicolumn{1}{c}{ Controls } \\
\hline Male (\%) & $13(72)$ & $11(61)$ \\
Female (\%) & $5(28)$ & $7(39)$ \\
Gestational age (weeks) (median (range)) & $28(24-32)$ & $28(23-32)$ \\
Birthweight (g) (median (range)) & $1204(751-1810)$ & $1262(593-1868)$ \\
Small for gestational age (\%) & $2(11)$ & $2(11)$ \\
Apgar score at 1 minute (median (range)) & $7(1-9)$ & $6(1-9)$ \\
Apgar score at 5 minutes (median (range)) & $9(4-10)$ & $9(1-10)$ \\
Apgar score at 5 minutes <5 & $1(6)$ & $2(11)$ \\
pH umbilical artery (median (range)) & $7 \cdot 28(6 \cdot 92-7 \cdot 41)$ & $7 \cdot 28(6 \cdot 87-7 \cdot 4)$ \\
pHa $\leqslant 7 \cdot 1(\%)$ & $4 / 16(25)^{\star}$ & $4 / 13(31)$ \\
Base excess ua (median (range)) & $6 \cdot 6(1 \cdot 7-17 \cdot 2)$ & $7 \cdot 8(1 \cdot 5-16 \cdot 9)$ \\
BEa $>12 \cdot 0$ mmol/1 & $4 / 16(25)$ & $4 / 13(31)$ \\
\hline
\end{tabular}

*Cord gases not available for all subjects.

Developmental delay and learning difficulties, normal motor development.

The characteristics of case and control infants at birth were similar (table 4). Low Apgar scores and acidaemia on umbilical cord blood assays were not predictive of cerebral palsy in this study. The cerebral palsy classification assigned to individual children correlated closely with the ultrasound findings in $\mathbf{1 4}$ $(78 \%)$ of the infants studied (table 5 ).

\section{Discussion}

Most children in this study with cerebral palsy had cystic lesions with preceding echodensities diagnosed by cerebral ultrasonography in the postnatal period. This finding confirms the observation in several studies that cystic lesions are a highly sensitive and specific predictor of neurodevelopmental outcome in preterm babies. ${ }^{11} 16-24$ The site and side of the lesions correlated well with the neurological findings in many of the children and were similar to the findings of Fawer $e t a l^{8}$ in terms of severity of disability.

Two of the cases had no cystic lesion in the postnatal period. One of these had a very uncomplicated neonatal course and had only two scans on days 1 and 8 , and one can only speculate whether a lesion would have been diagnosed at a later stage. The other infant had serial ultrasound scans with intraventricular haemorrhage and mild ventricular dilatation, but no echodensity or cyst, and this raises the question whether some important lesions were undetected using the equipment available at the time. Minimal ventricular dilatation alone, in the absence of overt parenchymal cerebral lesions, has been associated with subsequent neurodevelopmental impairment in some studies. ${ }^{825}$ It has been assumed that in the cases with adverse outcome the dilatation in the lateral ventricles is a manifestation of periventricular white matter damage and shrinkage. Alternatively, it may be that cerebral palsy originates in the postneonatal period in a proportion of preterm infants.

The control infant with a cystic lesion had developmental delay and learning difficulties at follow up, suggesting that the pathogenesis of other disabilities may overlap with that of cerebral palsy. This finding also highlights the importance of long term follow up of infants with abnormalities to assess disability of a cognitive nature. ${ }^{26}$

Unlike the study by Bejar, ${ }^{4}$ none of the cysts in this study was diagnosed in the first 24 or 72 hours. However, six infants had cysts diagnosed before the 10th postnatal day and the onset of these lesions may have preceded delivery. In two cases echodensities were present in the first 24 hours with no previous normal scan; this is consistent with an antenatal antecedent. In one other case an echodensity was diagnosed in the first 24 hours but the cyst did not develop until day 11 . Of the cysts apparent at around 6 weeks, review of the ultrasound reports showed a broad spectrum of times at which the lesion was first noted, giving an overall range of five to 51 days. The most likely explanation for this range of times is that the origins of preterm cerebral palsy do not lie in one specific time period but are spread throughout perinatal and postnatal life.

Adverse antenatal events occurred more often in cases than controls and more commonly in those with early and intermediate onset cystic lesions. The small numbers in the study preclude statistical analysis of individual factors, but a review of the case histories of the infants with early onset cysts supports the hypothesis that antenatal complications are associated with the ischaemic lesions sustained by these children. Antenatal complications occur frequently in preterm babies with cerebral palsy and it may be that in some children the lesion develops in utero and in others the insult leads to a primed individual developing or extending an ischaemic lesion in the postnatal period.

This study has thrown some light on the

Table 5 Description of cases of cerebral palsy

\begin{tabular}{cllll}
\hline $\begin{array}{l}\text { Case } \\
\text { No }\end{array}$ & $\begin{array}{l}\text { Gestational } \\
\text { age }\end{array}$ & Cystic lesion & $\begin{array}{l}\text { Earliest report } \\
\text { of cysts (day) }\end{array}$ & Cerebral palsy type \\
\hline 1 & 26 & Bilateral cystic, PVL right >left & 5 & Left hemiplegia \\
2 & 30 & Right parietal cyst (huge)/left PVL & 8 & Spastic quadriplegia/vision less \\
3 & 26 & Left frontal cyst (large)/right cyst (small) & 9 & Spastic diplegia/developmental delay \\
4 & 27 & Right parietal cyst (huge) & 9 & Left hemiparesis \\
5 & 30 & Right porencephalic cyst & 9 & Left hemiparesis \\
6 & 28 & Right frontoparietal cyst (huge)/left cyst (small) & 9 & Spastic quadraparesis/developmental delay \\
7 & 27 & Left frontoparietal cyst (huge) & 10 & Right hemiparesis \\
8 & 28 & Left frontoparietal cyst (huge) & 11 & Right hemiplegia \\
9 & 28 & Bilateral occipital and parietal cystic PVL & 11 & Spastic diplegia \\
10 & 32 & Left multiple cysts & 13 & Right hemiplegia/hearing loss \\
11 & 28 & Left posterolateral cysts & 15 & Spastic quadriplegia \\
12 & 30 & Left multiple cysts (extensive PVL) & 19 & Right hemiplegia/delayed speech \\
13 & 31 & Bilateral PVL/left frontal, right parietal & 25 & Spastic quadraparesis/dev delay/vision loss \\
14 & 29 & Left cystic PVL & 31 & Spastic diplegia \\
15 & 24 & Right frontoparietal cysts & 49 & Left hemiplegia \\
16 & 24 & Bilateral frontoparietal cysts & 51 & Spastic quadriplegia/legs $>$ arms \\
17 & 32 & 2 Scans, poor views/no cysts seen & & Spastic quadriplegia \\
18 & 31 & No cysts & & \\
& & & &
\end{tabular}


relation between ultrasound abnormalities, clinical events, and cerebral palsy in the preterm infant. Sufficient numbers to test the hypotheses raised would require a large multicentre study with careful attention to reproducibility of reporting of cerebral ultrasound abnormalities.

We thank the management group of the Oxford Register of Early Childhood Impairment (ORECI) for permission to use the register; Miss Rosemary King, administrative coordinator, for extracting data from the register; and colleagues at the National Perinatal Epidemiology Unit for commenting on drafts.

Dr D J Murphy is funded by Action Research.

Dr Johnson is funded by the Department of Health.

\section{Appendix 1}

DEFINITION OF ANTENATAL CHARACTERISTICS

Pre-existing maternal disease Endocrine disease other than diabetes; renal disease diagnosed by biochemical or radiological variables, or ongoing dialysis or the presence of renal transplantation, diabetes, respiratory or cardiovascular disease; other chronic diseases.

Antepartum haemorrhage Vaginal bleeding after 20 weeks gestation regardless of aetiology after exclusion of local haemorrhage of genital tract.

Placental abruption Severe haemorrhage (at least $200 \mathrm{ml}$ ) after 20 weeks gestation with at least two of the following: a clinical diagnosis (painful haemorrhage with a tense uterus); evidence of substantial retroplacental clot at delivery; or histological evidence of abruption.

Prolonged rupture of membranes Rupture of the membranes for more than 24 hours.

Chorioamnionitis Infection/inflammation of the membranes diagnosed by at least two of the following: clinical evidence (pyrexia, tender uterus, purulent liquor); microbiological or histological evidence.

Maternal infection Urinary tract infection or pyelonephritis (confirmed on mid stream urine); fever $\left(>38.5^{\circ} \mathrm{C}\right)$ of more than 24 hours; any other microbiologically confirmed infection other than chorioamnionitis.

Pre-eclampsia The presence of hypertension (diastolic blood pressure $\geqslant 90 \mathrm{~mm} \mathrm{Hg}$ ) and proteinuria (with or without biochemical and haematological changes).

Intrauterine growth retardation Ultrasound diagnosis of a weight more than 2 standard deviations below the mean using John Radcliffe percentile charts, estimated by serial measurements of the abdominal circumference.

Small for gestational age Birthweight more than 2 standard deviations below the mean as defined by percentile charts used at the John Radcliffe Hospital.

\section{Appendix 2}

DEFINITION OF POSTNATAL CHARACTERISTICS

Hyaline membrane disease Clinical diagnosis supported by chest $x$ ray picture and specifying whether surfactant was administered.

Pneumothorax Clinical diagnosis supported by chest $x$ ray picture and requiring a chest drain.

Hypotension Mean blood pressure $<30 \mathrm{~mm}$ $\mathrm{Hg}$ in the first 24 hours.

Patent ductus arteriosus treatment Clinical diagnosis and specifying whether fluid restriction, indomethacin, or surgical ligation were required.

Sepsis Clinical diagnosis supported by microbiological evidence of infection.

Necrotising enterocolitis Clinical and radiological diagnosis, specifying whether surgery was required.

1 Escobar GJ, Littenberg B, Petitti DB. Outcome among surviving very low birthweight infants: a meta-analysis. Arch Dis Child 1991; 66: F204-11.

2 Leviton A, Paneth N. White matter damage in preterm newborns - an epidemiologic perspective. Early Hum Dev 1990; 24: 122 .

3 Calvert SA, Hoskins EM, Fong KW, Forsyth SC. Etiological factors associated with the development of periventricular factors associated with the development of periven

4 Bejar R, Wozniak P, Allard M, Benirsche K, Vaucher Y, Coen $\mathrm{R}$, et al. Antenatal origin of neurologic damage in newborn infants. 1. Preterm infants. Am $\mathcal{F}$ Obstet Gynecol 1988; 159: 357-63.

5 Sinha SK, D'Souza SW, Rivlin E, Chiswick ML. Ischaemic brain lesions diagnosed at birth in preterm infants: clinical events and developmental outcome. Arch Dis Child 1990 65: $1017-20$.

6 Fujimoto S, Togari H, Yamaguchi N, Mizutani F, Suzuki S, Sobajima $\mathrm{H}$. Hypocarbia and cystic periventricular leukomalacia in premature infants. Arch Dis Child 1994; 71: F107-F10.

7 Weindling AM, Rochefort MJ, Calvert SA, Fok T, Wilkinson A. Development of cerebral palsy after ultraWilkinson A. Development of cerebral palsy after ultrasonographic detection of periventricular cysts
born. Dev Med Child Neurol 1985; 27: 800-6.

8 Fawer CL, Diebold P, Calame A. Periventricular leucomalacia and neurodevelopmental outcome in preterm infants. Arch Dis Child 1987; 62: 30-6.

9 Trounce JQ, Shaw DE, Levene MI, Rutter N. Clinical risk factors and periventricular leucomalacia. Arch Dis Child 1988; 63: 17-22.

10 Levene MI. Cerebral ultrasound and neurological impairment: telling the future. Arch Dis Child 1990; 65: 469-71.

11 Graziani LJ, Pasto M, Stanley C, Pidcock F, Desai H, Desai $S$, et al. Neonatal neurosonographic correlates of cerebral S, et al. Neonatal neurosonographic correlates of cer

12 Petterson B, Nelson KB, Watson L, Stanley F. Twins, triplets and cerebral palsy in births in Western Australia in the 1980s. BMf 1993; 307: 1239-43.

13 Johnson A, King R. A regional register of early childhood impairments: a discussion paper. Community Med 1989; 11: 352-63.

14 OSIRIS Collaborative Group. Early versus delayed neonatal administration of a synthetic surfactant - the judgement of OSIRIS. Lancet 1992; 340: 1363-9.

15 Gardner M, Altman D. Confidence intervals and statistical guidelines. In: Statistics with confidence. London: BMJ gublishing Group, 1989.

16 Graham M, Trounce JQ, Levene MI, Rutter N. Prediction of cerebral palsy in very low birthweight infants: prospective ultrasound study. Lancet 1987; ii: 593-6.

17 Low JA, Galbraith RS, Sauerbrei EE, Muir DW, Killen ML Pater E, et al. Motor and cognitive development of infants with intraventricular hemorrhage, ventriculomegaly, or periventricular parenchymal lesions. Am $\mathcal{f}$ Obstet Gynecol 1986; 155: 750-6.

18 de Vries LS, Dubowitz V, Lary S, Whitelaw A, Dubowitz LMS, Kaiser A, et al. Predictive value of cranial ultrasound in the newborn: a reappraisal. Lancet 1985: 137-40.

19 Cooke RWI. Early and late cranial ultrasonographic appearances and outcome in very low birthweight infants. Arch Dis Child 1987; 62: 931-7.

20 Bozynski MEA, Nelson MN, Genaze D, Rosati-Skertich C, Matalon TAS, Vasan U, et al. Cranial ultrasonography and the prediction of cerebral palsy in infants weighing $\leqslant 1200$ grams at birth. Dev Med Child Neurol 1988; 30: 342-8.

21 Pidcock FS, Graziani LJ, Stanley C, Mitchell DG, Merton $D$. Neurosonographic features of periventricular echodensities associated with cerebral palsy in preterm infants. f Pediatr 1990; 116: 417-22.

22 Weisglas-Kuperus N, Baerts W, Fetter WPF, Sauer PJJ. Neonatal cerebral ultrasound, neonatal neurology and perinatal conditions as predictors of neurodevelopmental outcome in very low birthweight infants. Early Hum Dev 1992; 31: 131-48.

23 van de Bor M, den Ouden L, Guit GL. Value of cranial ultrasound and magnetic resonance imaging in predicting neurodevelopmental outcon

24 Pinto-Martin JA, Riolo S, Cnaan A, Holzman C, Susser MW, Paneth N. Cranial ultrasound prediction of disabling and non-disabling cerebral palsy at age two in a low birthweight population. Pediatrics 1995; 95: 249-54.

25 Stewart AL, Thorburn RJ, Hope PL, Goldsmith M, Lipscombe AP, Reynolds EOR. Ultrasound appearance of the brain in very preterm infants and neurodevelopmental outcome at 18 months of age. Arch Dis Child 1983; 58: 598-604.

26 Roth SC, Baudin J, McCormick DC, Edwards AD, Townsend J, Stewart AL, et al. Relation between ultrasound appearance of the brain of very preterm infants and neurodevelopmental impairment at eight years. Dev Med Child Neurol 1993; 35: 755-68. 